НЕВСКАЯ Татьяна Александровна - кандидат политических наук, старший преподаватель кафедры политологии и социологии политических процессов социологического факультета МГУ им. М.В. Ломоносова (Nevskaya_t@mail.ru)

\title{
ОСОБЕННОСТИ ГОЛОСОВАНИЯ В ПЕРИОД ПАНДЕМИИ: МЕЖДУНАРОДНЫЙ ОПЫТ И РОССИЙСКАЯ ПРАКТИКА
}

\begin{abstract}
Аннотация. Актуальность исследуемого вопроса определяется потенциальной возможностью перенесения даты выборов в условиях распространения инфекции COVID-19. Пандемия поставила под вопрос возможность соблюдения основных этапов выборов, а также обусловила необходимость их проведения в новых, экстремальных условиях, в которых правительствам необходимо было разработать, а затем в краткие сроки реализовать комплекс мер в целях защиты жизни и здоровья граждан. В настоящей статье автор анализирует проблему проведения выборов в условиях пандемии в сравнительном аспекте: международный опыт был представлен в рамках сопоставления с российским. Автор делает акцент на наиболее значимых и требовавших разрешения вопросах, связанных с избирательными кампаниями в 2020 г. в РФ и в зарубежных странах, оценивает преимущества и недостатки распространения форм и методов дистанционного голосования.
\end{abstract}

Ключевые слова: выборы, избирательная кампания, голосование, пандемия, COVID-19, чрезвычайная ситуация, чрезвычайное положение, режим повышенной готовности

B ирус COVID-19, ставший причиной пандемии, вызвал изменения во всех сферах жизни в странах, столкнувшихся с распространением данной болезни. В новых условиях вынуждены были осуществлять свою деятельность не только экономические, культурные, но и политические институты. Одной из наиболее значимых проблем политической практики разных стран стала организация и проведение выборов.

В силу необходимости недопущения дальнейшего распространения эпидемии правительства как в России, так и за рубежом вынуждены были принимать соответствующие меры, призванные обезопасить жизнь и здоровье граждан, желающих проявить активную гражданскую позицию. Это актуализирует значимость изучения организации и проведения выборов с точки зрения трансформации их форм и методов, применяемых специалистами при работе с населением. Целесообразно также произвести сравнение особенностей проведения выборов в РФ и за рубежом с учетом реализации нововведений, связанных с пандемией, касающихся как соблюдения необходимых санитарно-профилактических требований, так и этапов избирательных кампаний.

Проведение процедуры выборов в условиях пандемии обусловило как иную их организацию, так и значительное распространение тех форм, которые ранее не пользовались широкой популярностью у граждан, особенно старшего возраста. К их числу относятся мобильное голосование, досрочное голосование, голосование по почте, а также иные способы, доступные для населения, желающего выразить свою гражданскую позицию либо дистанционно, либо при минимизировании числа социальных контактов.

Несмотря на рост и распространение заболеваемости, государства с демократическим режимом на основании 21-й статьи Всеобщей декларации прав чело- 
века 1948 г. должны были гарантировать своим гражданам регулярное проведение выборов 1 .

Необходимость проведения выборов с определенной периодичностью закреплялась также некоторыми иными документами международного уровня, в частности Конвенцией о стандартах демократических выборов, избирательных прав и свобод в государствах - участниках Содружества Независимых Государств ${ }^{2}$, положения которой также содержат отсылки к Всеобщей декларации прав человека и Международному пакту о гражданских и политических правах 3 , устанавливающим подлинность выборов и необходимость волеизъявления народа.

С точки зрения оценки опыта подготовки и проведения выборов в условиях пандемии в РФ следует отметить, что в первую очередь Центральная избирательная комиссия подготовила специальный проект, с которым члены избирательных комиссий, наблюдатели и граждане могли ознакомиться посредством просмотра электронной презентации. Последняя наглядно демонстрировала те изменения, с которыми предстояло столкнуться населению во время процедуры голосования. Новый стандарт должен был применяться с 1 июля 2020 г. ${ }^{4}$

Главным нововведением и вместе с тем обязательным условием проведения процедуры выборов, призванным обеспечить ее безопасность, было использование работниками избирательных комиссий и голосующими средств индивидуальной защиты. Кроме того, 2 сентября 2020 г. ознаменовало собой новый этап выборов: был открыт прием заявок на голосование на дому. Данная мера была призвана обеспечить возможность участия в выборах тем россиянам, которые не могли прибыть на избирательные участки в силу различных уважительных причин. При этом за избирательными комиссиями сохранялось право отказать в приеме подобного заявления со стороны граждан в том случае, если причина была сочтена ими не уважительной 5 . Аналогичные заявления можно было подать не только в избирательные комиссии, но также и на едином портале госуслуг. В рамках реализации процедуры голосования на дому сотрудникам необходимо было дезинфицировать ручку входной двери гражданина, по адресу которого они прибывали, после чего оставить переносную урну у его двери вместе с маской, бюллетенем, шариковой ручкой в одном пакете и дожидаться завершения голосования ${ }^{6}$.

Значимым опытом голосования в 2020 г. было его проведение в течение не одного, а нескольких дней. Это представляется полезным опытом с точки зрения организации процедуры голосования. Возможность подать свой голос за кандидата либо партию не только в единый день голосования, но и в течение

1 Всеобщая декларация прав человека. Принята резолюцией 217A (III) Генеральной Ассамблеи ООН от 10 декабря 1948 г. Доступ: https://www.un.org/ru/documents/decl_conv/ declarations/declhr.shtml (проверено 22.07.2021).

2 Конвенция о стандартах демократических выборов, избирательных прав и свобод в государствах - участниках Содружества Независимых Государств. Доступ: https://docs.cntd. ru/document/901836765 (проверено 22.07.2021).

3 Международный пакт о гражданских и политических правах. Принят резолюцией 2200A (XXI) Генеральной Ассамблеи от 16 декабря 1966 г. Доступ: https://www.un.org/ru/ documents/decl_conv/conventions/pactpol.shtml (проверено 22.07.2021).

4 Голосование в условиях пандемии: международный опыт и гарантии безопасности. - РАПСИ. 02.06.2020. Доступ: http://rapsinews.ru/incident_publication/20200602/305878205. html (проверено 22.07.2021).

5 Мисливская Г.В. 2020. В России начинается прием заявлений на надомное голосование 13 сентября. - Российская газета. 02.09.2020. Доступ: https://rg.ru/2020/09/02/vrossii-nachinaetsia-priem-zaiavlenij-na-nadomnoe-golosovanie-13-sentiabria.html (проверено 22.07.2021).

6 Общероссийское голосование в условиях пандемии: как будет обеспечена безопасность здоровья участников? Доступ: https://www.garant.ru/news/1381208/ (проверено 22.07.2021). 
6 дней до него позволила гражданам прибывать на участок в удобное для себя время.

Новым явлением в рамках голосования в 2020 г. в целях недопущения роста заболеваемости было проведение голосования на улицах населенных пунктов. Это объясняется тем, что голосование в помещении могло создать большую угрозу инфицирования избирателей.

Необходимо отметить, что, несмотря на сложность и непривычность для российских граждан реализации многих мер, которые были необходимы на выборах в условиях пандемии, в целом иностранные эксперты положительно оценили опыт организации и проведения голосования в РФ в 2020 г.

В частности, вице-председатель партии «Альтернатива болгарского возрождения» Л. Ганчева отмечала, что многие способы, позволяющие облегчить процесс голосования, сделать его дистанционным и доступным, исключить обязательность прибытия граждан на избирательные участки, отсутствуют в Болгарии. К их числу следует отнести комплексы обработки избирательных бюллетеней (КОИБы) - специальные электронные устройства для подсчета голосов избирателей, а также электронное голосование ${ }^{1}$, которое являлось значимым шагом для перехода гражданской активности в медиапространство [Невская 2020]. Отдельно отмечалась также прозрачность процедуры выборов, что подтверждалось значительным числом наблюдателей, присутствовавших на избирательных участках ${ }^{2}$.

Как было указано выше, в России и за рубежом эпидемия COVID-19 оказала значительное влияние не только на особенности проведения самих выборов, но также и на некоторые стадии избирательного процесса. Под последним, в свою очередь, следует понимать комплекс правоотношений, возникающих по поводу организации и проведения выборов [Авакьян 1996: 9]. Правовой подход к исследованию сущности избирательного процесса позволяет рассматривать его как определенную политическую деятельность и вместе с тем как совокупность норм, призванных ее регламентировать [Конституционное... 2000: 433].

Регулирование деятельности в рамках выборов позволяет говорить о ее системности и, как следствие, подразделении на ряд определенных этапов. К их числу следует относить, в частности, назначение дня выборов, образование избирательных округов и участков, составление списков избирателей, предвыборную агитацию и некоторые иные, обязательные с точки зрения организации и проведения выборов этапы [Конституционное... 2000: 434]. Несмотря на то что вплоть до настоящего времени исследователи не выработали единый подход к классификации данных этапов, распространение пандемии оказало влияние прежде всего на наиболее значимый из них, без которого невозможна регламентация избирательного процесса, - назначение даты выборов.

Назначение выборов предполагает определение конкретного дня проведения голосования по выборам в представительные органы либо избираемых населением должностных лиц государства. Определение этой даты имеет решающее значение, несмотря на то что, по сути, в ходе избирательной кампании она является конечной. Однако именно от нее зависит временной период, в рамках которого кандидатам на выборные должности, а также партиям предстоит реализовать в избирательной борьбе весь комплекс агитационных мероприятий.

Проблема переноса даты выборов являлась наиболее существенной в рамках проведения голосования в 2020 г. Помимо этого, в ряде государств те огра-

1 Опыт России по проведению голосования в период пандемии имеет международное значение - эксперты. - Seldon.News. 28.07.2020. Доступ: https://news.myseldon.com/ru/ news/index/233112144 (проверено 23.06.2021).

2 Там же. 
ничительные меры, которые были введены, не позволяли проводить голосование в изначально обозначенные сроки. Примером таких стран являлись Великобритания, Боливия, Италия, Кипр, Сербия, Америка и некоторые другие.

В рамках анализа данной проблемы целесообразно обратиться к нормам международного законодательства. В частности, п 1. ст. 4 Международного пакта о гражданских и политических правах гласит, что государства, подписавшие данный документ, имеют право отступить от своих обязательств ввиду ситуаций, создающих опасность для жизни и здоровья, а также в результате введения чрезвычайного положения в том случае, если это не влечет за собой «дискриминации исключительно на основе расы, цвета кожи, пола, языка, религии или социального происхождения» 1 .

В Российской Федерации в связи с распространением коронавируса не было введено чрезвычайное положение, однако постановлением Правительства РФ от 2 апреля 2020 г. вводился режим повышенной готовности. Последний, в свою очередь, открыто не отождествлялся с чрезвычайной ситуацией, однако в законе приводилась одинаковая регламентация действий в случае как чрезвычайных ситуаций, так и режима повышенной готовности, что де-факто позволяло трактовать их как идентичные понятия и ставило под угрозу проведение выборов в назначенную дату.

Наряду с российским государством, перенос даты голосования также был поставлен на повестку дня в странах, где распространился коронавирус. В то же время чрезвычайное положение вводилось не повсеместно: так, на территории Франции, Великобритании, Сирии и Ирана действовал режим чрезвычайной ситуации, с введением которой в указанных государствах были приняты специальные законы в связи с распространением эпидемии.

Отличия в политических системах России и зарубежных стран являются ключевым фактором, детерминирующим специфику организации сопровождения избирательных кампаний [Невская 2019: 57]. Вместе с тем в условиях пандемии организация и проведение последних отличались сходными проблемами. Предвыборная кампания в Польше была самой длительной за весь период проведения выборов в государстве. Несмотря на то что первый тур выборов был запланирован только на 10 мая, ряд кандидатов начали ее еще в ноябре 2019 г.

В свою очередь, в таких странах, как Великобритания и Сербия, основанием для переноса выборов стали решения уполномоченных государственных органов и должностных лиц, подготовленные на базе соответствующих рекомендаций, выработанных органами здравоохранения, а также национальными центральными избирательными органами.Однако далеко не все государства, несмотря на реальную угрозу распространения эпидемии, решились на перенос даты выборов. Наиболее яркими примерами выступили Молдова и Беларусь, где выборы прошли в соответствии с конституционными положениями. При этом активно использовались мероприятия по агитации населения, которые, однако, в силу опасности заражения, также переместились преимущественно в электронный формат (ярким примером являются США).

Парламентская ассамблея Совета Европы (ПАСЕ) не направила наблюдателей на президентские выборы в Молдову в силу тех ограничений, которые в отдельных государствах были введены в силу пандемии. Голосование происходило в установленные сроки и в обычном режиме, однако с соблюдением необходимых санитарных и профилактических норм. Лидером по использованию цифровых

1 Международный пакт о гражданских и политических правах. Принят резолюцией 2200A (XXI) Генеральной Ассамблеи от 16 декабря 1966 г. Доступ: https://www.un.org/ru/ documents/decl_conv/conventions/pactpol.shtml (проверено 22.07.2021). 
технологий для голосования являлись Соединенные Штаты в силу того, что они вышли на первые позиции в мире по числу летальных случаев от коронавируса. В этой связи агитационные методы, применяемые партиями в 2020 г., существенно отличались от опыта предыдущих лет. При этом положительным моментом по сравнению с проходившими ранее избирательными кампаниями являлось отсутствие необходимости личной встречи с избирателями, что позволяло кандидатам существенно сэкономить на перелетах из одного штата в другой. Однако это привело к росту расходов на пиар-кампании в социальных сетях.

Подводя итоги, следует отметить, что российский и международный опыт организации и проведения голосования в период пандемии не только продемонстрировал сравнительно высокую степень готовности правительств к работе в чрезвычайных условиях, но и позволил усовершенствовать процедуру голосования, в которой стали преобладать удобные и безопасные дистанционные методы. В свою очередь, подход разных стран к решению вопроса о возможности перенесения сроков голосования продемонстрировал стремление одних государств неуклонно соблюдать конституционные принципы, в то время как другие пользовались законодательно закрепленной возможностью отступления от них в целях сохранения жизни и здоровья своих граждан.

\section{Список литературы}

Авакьян С.А. 1996. Конституционное право: методическое руководство к семинарам. М.: Изд-во МГУ. 61 с.

Конституционное государственное право зарубежных стран. В 4 т.: учебник (отв. ред. Б.А. Страшун). 3-е изд., обновл. и. дораб. 2000. М.: БЕК. Т. 1-2. 896 с.

Невская Т.А. 2019. Информационно-аналитическое сопровождение избирательных кампаний: российский и зарубежный опыт. - Социодинамика. № 10. C. 55-64.

Невская Т. А. 2020. Гражданский активизм как ресурс политического администрирования медиапространства: российский и международный опыт. Социодинамика. № 9. С. 18-29.

\section{PECULIARITIES OF VOTING DURING PANDEMIC PERIOD: INTERNATIONAL EXPERIENCE AND RUSSIAN PRACTICE}

\footnotetext{
Abstract. The relevance of the issue under study is determined by the potential for postponing the election date in the context of the spread of COVID-19 infection. The pandemic called into question the ability to comply with the main stages of elections, and also made it necessary to hold them in new, extreme conditions in which governments needed to develop and then quickly implement a set of measures to protect the life and health of citizens.

In this article, the author analyzes the problem of holding elections in a pandemic in a comparative aspect: the international experience was presented in the framework of comparison with the Russian one. The author focuses on the most significant and requiring resolution issues related to election campaigns in 2020 in the Russian Federation and in foreign countries, assesses the advantages and disadvantages of the dissemination of forms and methods of remote voting.
}

Keywords: elections, election campaign, voting, pandemic, COVID-19, emergency, state of emergency, high alert 